\title{
ChemComm
}

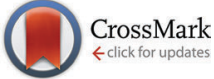

Cite this: Chem. Commun., 2016, 52,745

Received 15th July 2015

Accepted 4th November 2015

DOI: $10.1039 / c 5 c c 05889 a$

www.rsc.org/chemcomm

\section{Substituted ferrocenes and iodine as synergistic thermoelectrochemical heat harvesting redox couples in ionic liquids $\dagger$}

\author{
E. H. B. Anari, ${ }^{a}$ M. Romano, ${ }^{b}$ W. X. Teh, ${ }^{a}$ J. J. Black, ${ }^{a}$ E. Jiang, ${ }^{a}$ J. Chen, ${ }^{b}$ T. Q. To, ${ }^{a}$ \\ J. Panchompoo ${ }^{a}$ and L. Aldous*a
}

\begin{abstract}
Combining ferrocene and iodine results in enhanced thermoelectrochemical (or thermogalvanic) waste heat harvesting abilities, for both the Seebeck coefficient and the overall power output. All systems displayed a mixture of ferrocene, ferrocenium, iodine and triiodide. The observed enhancement correlates with lower electron-density on the ferrocene; the synergistic improvement observed for mixtures of substituted ferrocenes and iodine is attributed to the formation of charge-transfer complexes. Combining dibutanoylferrocene and iodine resulted in the highest Seebeck coefficient of $1.67 \mathrm{mV} \mathrm{K}^{-1}$.
\end{abstract}

Worldwide, heat is converted into electricity on a tremendous scale. The Seebeck effect allows arguably the simplest process, whereby a difference in temperature can be converted directly into electrical power with no moving parts. ${ }^{1}$ This simplicity has made it a hallmark energy system of unmanned space exploration. ${ }^{1}$ The majority of thermoelectric systems are based upon solid-state semiconductor devices, typically containing rare metalloids such as $\mathrm{Bi}_{2} \mathrm{Te}_{3},{ }^{2}$ and which suffer from rigidity, expense and low efficiencies. ${ }^{1}$

Thermoelectrochemical cells containing a liquid electrolyte with a suitable redox couple can also generate electrical power from a temperature difference. These systems offer many advantages such as flexibility, ${ }^{3}$ low cost ${ }^{4}$ and are suited to the harvesting of low-grade heat. ${ }^{5}$

The Seebeck coefficient $\left(S_{\mathrm{e}}\right.$, eqn (1)) expresses the potential difference $(\Delta E)$ generated across two electrodes sharing a common electrolyte, as a function of their temperature difference $(\Delta T){ }^{6}$ Dissolved redox couples at different temperatures will have a freeenergy difference proportional to the entropy difference between the redox states $(\Delta S)$. Unlike in semi-conductors, these liquid, solid

\footnotetext{
${ }^{a}$ School of Chemistry, UNSW Australia, Sydney, NSW 2052, Australia.

E-mail: l.aldous@unsw.edu.au

${ }^{b}$ Intelligent Polymer Research Institute, Innovation Campus,

University of Wollongong, Wollongong, NSW 2522, Australia

$\dagger$ Electronic supplementary information (ESI) available: Experimental, raw data and determination of the ferrocene/ferrocenium ratios. See DOI: 10.1039/c5cc05889a
}

or gaseous electrochemical systems give rise to significant $S_{\mathrm{e}}$ values on the order of $\mathrm{mV} \mathrm{K}^{-1}$. ${ }^{7}$ This is important, as the maximum power is directly proportional to the $S_{\mathrm{e}}$ value, and the efficiency of heat conversion is proportional to the $S_{\mathrm{e}}$ squared. ${ }^{8}$

$$
S_{\mathrm{e}}=\frac{\Delta E}{\Delta T}=\frac{\Delta S}{n F}
$$

The majority of studies into thermoelectrochemical cells have employed aqueous electrolytes containing inorganic redox couples. A prime example is aqueous potassium ferrocyanide/ ferricyanide solutions, which exhibit a relatively large $S_{\mathrm{e}}$ on the order of $c a .-1.4 \mathrm{mV} \mathrm{K}^{-1.3,4}$ Short-lived systems can exceed this, recently reaching $+13.6 \mathrm{mV} \mathrm{K}^{-1}$. ${ }^{9}$ However, the volatility of water can be a major limitation for thermoelectrochemical cells and so ionic liquids (ILs) have been proposed as non-volatile electrolytes for thermoelectrochemical cells. ${ }^{5}$ IL-based thermoelectrochemical cells can be operated at temperatures above $100{ }^{\circ} \mathrm{C}$ with no degradation, as a result of the high thermal stability and the low (near-zero) vapour pressure of many ILs. ${ }^{5 a}$ ILs are known to be highly structured liquids, and entropy is highly significant in many processes in ILs. ${ }^{10}$ In 2013 a Co(II)/Co(III) complex reached $S_{\mathrm{e}}$ values of 1.40 to $1.88 \mathrm{mV} \mathrm{K}^{-1}$ in a range of ILs. ${ }^{5 b}$

Despite progress, relying upon the entropy change inherent in a single redox process is clearly self-limiting; too great an entropy change generally correlates with lower exchange current densities and necessitates an electrocatalytic material. Electrocatalysis in ILs is a relatively new and poorly understood area. ${ }^{11}$ In an effort to move beyond this limiting factor, this work investigates combining two redox couples based upon ferrocene and iodine. When employed individually they represent poor thermoelectrochemical redox couples, but together they display a synergistically enhanced performance. This opens new routes to maximising performance by overcoming the limitations noted above.

Both the ferrocene|ferrocenium ${ }^{12}$ and iodide|triiodide ${ }^{13}$ redox couples find extensive uses in electrochemistry, and have been (separately) well characterised in ILs. Both ferrocenium-based ILs ${ }^{14}$ and iodide/triiodide-based $\mathrm{ILs}^{13}$ are known. Recently, combining 
redox couples has been beneficially employed in IL-based dye sensitised solar cells. ${ }^{15}$

In this work, redox couples were investigated by dissolving individual redox couples (ferrocene|ferrocenium and iodide|triiodide) and also by mixing ferrocene and iodide, which are in equilibrium with their ferrocenium triiodide salt (eqn (2)). The reaction between ferrocene and iodide has been the subject of extensive fundamental research relating to equilibrium constants and kinetics, ${ }^{16}$ although not in ILs.

$$
\mathrm{Fc}+\frac{3}{2} \mathrm{I}_{2} \rightleftharpoons \mathrm{Fc}^{+}+\left[\mathrm{I}_{3}\right]^{-}
$$

In addition to the ferrocenium triiodides being inherently electroactive, the overall equilibrium is also temperaturesensitive. While ferrocenium species rapidly decomposes in oxygenated organic solvents, ${ }^{17}$ they were found to be stable when dissolved in the ionic liquid 1-ethyl-3-methyl-imidazolium bis(trifluoromethylsulfonyl)imide ([Emim] $\left.\left[\mathrm{NTf}_{2}\right]\right)$, hence all studies were performed in this IL.

Several substituted ferrocenes were synthesised (full details in $\mathrm{ESI} \dagger)$. They are ferrocene $(\mathrm{Fc})$, acetylferrocene ( $\mathrm{AcFc}$ ), ethylferrocene (EtFc), dibutylferrocene (DiBuFc) and dibutanoylferrocene (DiBoylFc).

The Seebeck coefficients $\left(S_{\mathrm{e}}\right)$ were measured in a U-shaped assembly (U-cell, full details in the ESI $\dagger$ ) using platinum electrodes. Fig. 1(a) displays the potential difference of $15 \mathrm{mM}$ $\mathrm{Fc} / 15 \mathrm{mM} \mathrm{Fc}^{+}(\mathbf{\Delta}), 15 \mathrm{mM} \mathrm{I} / 15 \mathrm{mM}\left[\mathrm{I}_{3}\right]^{-}(\boldsymbol{O})$ and $30 \mathrm{mM}$

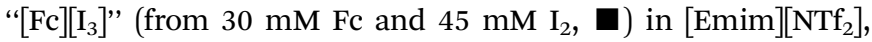
measured as a function of temperature; the corresponding $S_{\mathrm{e}}$ values are summarised in Table 1.

The value measured here for $\mathrm{Fc} \mid \mathrm{Fc}^{+}$is essentially identical to the value reported by Migita et al. $\left(+0.10 \pm 0.01 \mathrm{mV} \mathrm{K}^{-1}\right) .{ }^{18}$ The measured value for $\mathrm{I}^{-} \mid\left[\mathrm{I}_{3}\right]^{-}$is slightly lower than that reported by Abraham et al. $\left(+0.154 \mathrm{mV} \mathrm{K}^{-1}\right.$ in $\left.[\mathrm{Emim}]\left[\mathrm{NTf}_{2}\right]^{5 a}\right)$ although those samples were $c a$. 30 fold more concentrated.
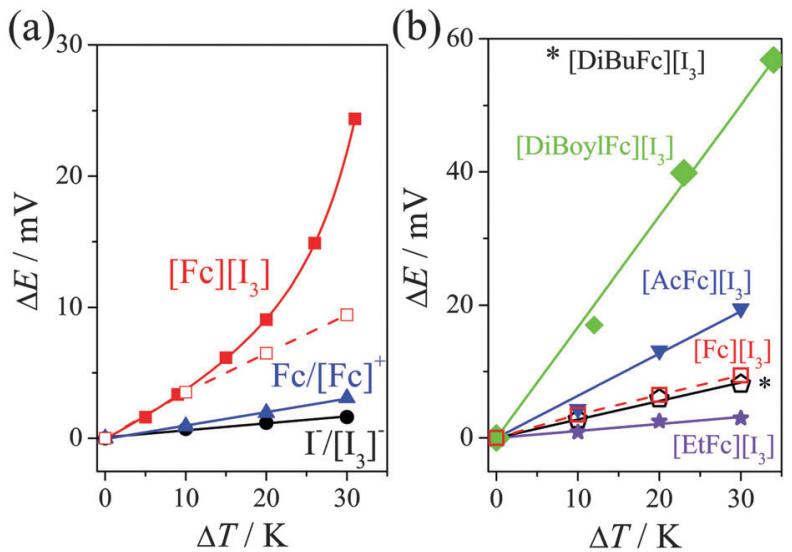

Fig. 1 (a) Potential difference recorded as a function of temperature for $15 \mathrm{mM} \mathrm{Fc} / 15 \mathrm{mM} \mathrm{Fc}^{+}(\bullet), 15 \mathrm{mM} \mathrm{I}^{-} / 15 \mathrm{mM}^{\left.-\mathrm{I}_{3}\right]^{-}}(\mathbf{\Delta})$ and $30 \mathrm{mM}$ of $[\mathrm{Fc}]\left[\mathrm{I}_{3}\right]$ ( $\square$ in U-tube, $\square$ in battery casing) in [Emim] $\left[\mathrm{NTf}_{2}\right]$. Also (b) potential difference for $30 \mathrm{mM}$ of $[\mathrm{Fc}]\left[\left[_{3}\right]\right.$ ( $\left.\square\right) 30 \mathrm{mM}[\mathrm{AcFc}]\left[I_{3}\right](\nabla), 30 \mathrm{mM}[\mathrm{EtFc}]\left[I_{3}\right]$

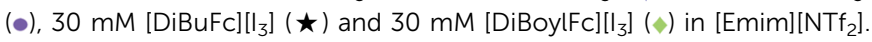
$T_{\text {cold }}=20^{\circ} \mathrm{C}$. Error bars are smaller than data points.
Table 1 Seebeck coefficients for various redox couples, determined from linear $\Delta E$ vs. $\Delta T$ plots (except*; estimated from $\Delta E$ at $\Delta T=30 \mathrm{~K}$ )

\begin{tabular}{ll}
\hline Redox couple in $[\mathrm{Emim}]\left[\mathrm{NTf}_{2}\right]$ & $\begin{array}{l}\text { Seebeck coefficient } / \mathrm{mV} \mathrm{K}^{-1} \\
\text { (value from CR2032 casing) }\end{array}$ \\
\hline $15 \mathrm{mM} \mathrm{Fc} / 15 \mathrm{mM}[\mathrm{Fc}]^{+}$ & $0.100 \pm 0.002$ \\
$15 \mathrm{mM} \mathrm{I} / 15 \mathrm{mM}\left[\mathrm{I}_{3}\right]^{-}$ & $0.057 \pm 0.003$ \\
$30 \mathrm{mM}[\mathrm{Fc}]\left[\mathrm{I}_{3}\right]$ & $0.813^{*}(0.291 \pm 0.002)$ \\
& \\
$30 \mathrm{mM}[\mathrm{EtFc}]\left[\mathrm{I}_{3}\right]$ & $0.106 \pm 0.008$ \\
$30 \mathrm{mM} \mathrm{[DiBuFc}]\left[\mathrm{I}_{3}\right]$ & $0.279 \pm 0.006$ \\
$30 \mathrm{mM} \mathrm{[AcFc}]\left[\mathrm{I}_{3}\right]$ & $0.636 \pm 0.033$ \\
$30 \mathrm{mM}[\mathrm{DiBoylFc}]\left[\mathrm{I}_{3}\right]$ & $1.669 \pm 0.045$
\end{tabular}

The $[\mathrm{Fc}]\left[\mathrm{I}_{3}\right]$ system is more complex, and interestingly displayed a non-linear potential $v s$ temperature trend. The $[\mathrm{Fc}]\left[\mathrm{I}_{3}\right]$ also displayed consistently higher potential values that that of the individual ferrocene and iodine systems. The non-linear trend was present during heating and cooling, displaying no hysteresis, although it is important to note that it took $c a .1 \mathrm{~h}$ for these values to stabilise.

A maximum potential of $c a .24 .4 \mathrm{mV}$ was achieved by $[\mathrm{Fc}]\left[\mathrm{I}_{3}\right]$ at $\Delta T=30 \mathrm{~K}$, which equates to an $S_{\mathrm{e}}$ of $c a .0 .83 \mathrm{mV} \mathrm{K}^{-1}$. Therefore the simple expedient of mixing $\mathrm{Fc}^{0}$ with $\mathrm{I}_{2}$ results in an $S_{\text {e }}$ value which (at $\Delta T=30 \mathrm{~K}$ ) equates to a 14 -fold increase over $\mathrm{I}^{-} /\left[\mathrm{I}_{3}\right]^{-}$alone, and a 5 -fold increase over the sum of the individual $\mathrm{Fc} / \mathrm{Fc}^{+}$and $\mathrm{I}^{-} /\left[\mathrm{I}_{3}\right]^{-}$redox couples, representing a significant synergy when the two are mixed to form $[\mathrm{Fc}]\left[\mathrm{I}_{3}\right]$. Further increases in temperature resulted in some instability due to gradual evaporation of the volatile materials from the open U-tube, and at $c a .100{ }^{\circ} \mathrm{C}[\mathrm{Fc}]\left[\mathrm{I}_{3}\right]$ underwent irreversible decomposition to form iron iodide.

The same systems were investigated in a platinum-coated CR2032 battery casing, which provides $2 \mathrm{~mm}$ electrode separation ( $c f .2 \mathrm{~cm}$ in the U-tube) and is more suited for power generation. The hermetically sealed casing also allowed higher temperature differences without any loss of the volatile redox compounds. In this case, the $[\mathrm{Fc}]\left[\mathrm{I}_{3}\right]$ initial trend matched that of the U-tube but deviated at higher temperatures $\left(S_{\mathrm{e}}=0.291 \pm\right.$ $0.002 \mathrm{mV} \mathrm{K}^{-1}$, hollow symbols in Fig. 1(a)). Nevertheless, the $S_{\mathrm{e}}$ value still displayed the synergy discussed above. The $S_{\mathrm{e}}$ value of $\mathrm{Fc} / \mathrm{Fc}^{+}$was also measured in the battery casing and found to be $0.081 \pm 0.001 \mathrm{mV} \mathrm{K}^{-1}$ (cf. $0.100 \pm 0.002 \mathrm{mV} \mathrm{K}^{-1}$ in the U-tube), and all systems gave ca. 20\% lower Seebeck coefficients in the battery casing. This is predominately due to a temperature drop from the heated exterior to the interior of the cell. In the U-tube (electrodes separated by $2 \mathrm{~cm}$ ) it took ca. $1 \mathrm{~h}$ for the potential values to stabilise, whereas in the battery casing ( $2 \mathrm{~mm}$ separation) it took only a few minutes (Fig. S3, $\mathrm{ESI} \dagger)$. In the battery casing there is more significant thermal convection, whereas in the U-tube the temperature-induced change in the equilibrium in eqn (2) appears to become more significant over time. This mirrors observations in aqueous systems where varying the electrode separation and electrode orientation to gravity can either increase or decrease power according to the precise redox couple utilised. ${ }^{19}$

The power discharge characteristics of the systems were also investigated in the battery casing. As demonstrated in Fig. 2, 


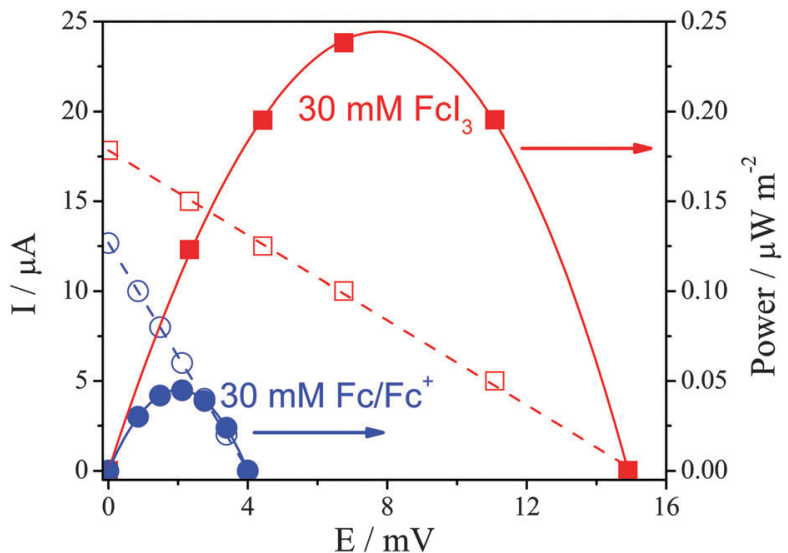

Fig. 2 Current-potential discharge trends, displaying power generated by $30 \mathrm{mM} \mathrm{Fc} / \mathrm{Fc}^{+}$(15 mM of each) (•) and $30 \mathrm{mM}$ of $[\mathrm{Fc}]\left[\mathrm{I}_{3}\right](\square)$ in $[\mathrm{Emim}]\left[\mathrm{NTf}_{2}\right]$ in a Pt-coated CR2032 battery casing at $\Delta T=50{ }^{\circ} \mathrm{C}\left(T_{\text {cold }}=30{ }^{\circ} \mathrm{C}\right)$.

$30 \mathrm{mM}[\mathrm{Fc}]\left[\mathrm{I}_{3}\right]$ generated significantly more power than $30 \mathrm{mM}$ $\mathrm{Fc} \mid \mathrm{Fc}^{+}$, largely due to the higher $S_{\mathrm{e}}$ value of the former. The precise charge carrier(s) involved in the $[\mathrm{Fc}]\left[\mathrm{I}_{3}\right]$ system is currently unknown. The power also refers to the steady-state conditions obtained after 10 min discharge. Given their differing diffusion coefficients ${ }^{12,13}$ and the possibility for both species to undergo Grotthuss-like conductivity, further work is required to investigate what happens to these systems under extended discharge conditions.

While the temperature-dependant equilibrium in the ferrocenium triiodide salt clearly has some influence, it does not explain the observed synergy resulting in the $S_{\mathrm{e}}$ increases. To investigate further, the ferrocene core was systematically altered by adding electron-donating (alkyl) or electron-withdrawing (alkanoyl) groups. Fig. 1(b) displays the potential differences measured for $45 \mathrm{mM} \mathrm{I}_{2}$ and $30 \mathrm{mM}$ of Fc $(\square), \operatorname{AcFc}(\boldsymbol{\nabla}), \operatorname{EtFc}(\bullet), \operatorname{DiBuFc}(\star)$ and DiBoylFc ( $)$ in [Emim] [NTf 2 ]. Table 1 lists the $S_{\mathrm{e}}$ values of all redox couple species studied in this work, and it was found that $30 \mathrm{mM}$ "[DiBoylFc][ $\left.\mathrm{I}_{3}\right]$ " possesses the highest $S_{\mathrm{e}}$ value of $1.67 \pm$ $0.05 \mathrm{mV} \mathrm{K}^{-1}$.

The trend in $S_{\mathrm{e}}$ values follows the order DiBoylFc $>$ AcFc $>$ Fc $>$ DiBuFc $>$ EtFc, which follows the anticipated electron density on the ferrocene centre from lowest to highest. The inversion of DiBuFc and EtFc is an exception to this trend, and is likely due to a subtle contribution from the alkyl chains to the overall entropy change.

In organic solvents, electron-donating groups on the ferrocene moiety (e.g. alkyl groups) shifts the equilibrium in eqn (2) towards the right, resulting in more triiodide product formed. ${ }^{16 a, b}$ This was investigated in $\left[\mathrm{Emim}_{[}\right]\left[\mathrm{NTf}_{2}\right]$ by cyclic voltammetry $(\mathrm{CV})$, and the oxidation potentials of the substituted ferrocenes followed the expected trend in the IL (Fig. S5, ESI†). Comparison of the potentials relative to those of $\mathrm{I}^{-} /\left[\mathrm{I}_{3}\right]^{-}$(Fig. S6, ESI $\dagger$ ) and use of the Nernst equation allows us to estimate (see ESI $\dagger$ for full discussion) that a $2: 3$ mixture of DiBuFc and $I_{2}$ should exist as $99.9 \%$ [DiBuFc $]\left[\mathrm{I}_{3}\right]$ (at $298 \mathrm{~K}$ ); for DiBoylFc only $c a$. $10 \%$ exists as $[\mathrm{DiBoylFc}]\left[\mathrm{I}_{3}\right]$. However, when ferrocene and iodine were investigated in the same system the situation was more complex.

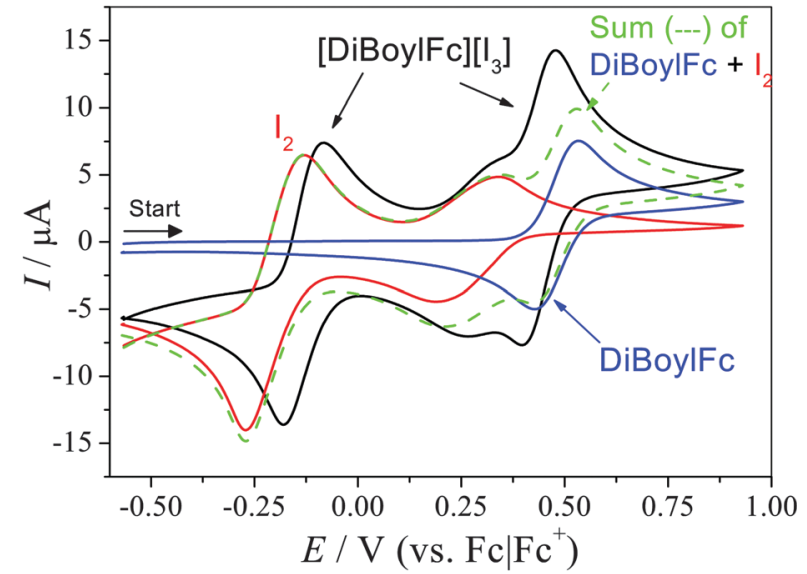

Fig. 3 CVs recorded for $15 \mathrm{mM}$ DiBoylFc, $22.5 \mathrm{mM} \mathrm{I}_{2}$, the additive sum of these two scans, and $15 \mathrm{mM}$ [DiBoylFc][I 3 . Scans recorded at a $1.6 \mathrm{~mm} \mathrm{Pt}$ electrode, $293 \mathrm{~K}, 50 \mathrm{mV} \mathrm{s}^{-1}$, and corrected to the $\mathrm{Fc}_{\mathrm{Fc}} \mathrm{Fc}^{+}$formal potential.

Fig. 3 displays CVs of $15 \mathrm{mM}$ DiBoylFc, $22.5 \mathrm{mM} \mathrm{I}_{2}$, and $15 \mathrm{mM}$ [DiBoylFc $]\left[\mathrm{I}_{3}\right]$; similar data for $[\mathrm{Fc}]\left[\mathrm{I}_{3}\right]$ and $[\mathrm{DiBuFc}]\left[\mathrm{I}_{3}\right]$ are included in the ESI. $\dagger$ When mixed, the $\mathrm{I}^{-} /\left[\mathrm{I}_{3}\right]^{-}$feature displayed a $c a .50 \mathrm{mV}$ anodic shift, the $\left[\mathrm{I}_{3}\right] / \mathrm{I}_{2}$ process was unchanged, while the DiBoylFc/[DiBoylFc] $]^{+}$peaks shifted $c a .50 \mathrm{mV}$ cathodically. Additionally, currents for the mixed ferrocenium triiodide systems were higher than expected, demonstrating some 'nonadditivity' of faradaic currents; this has been previously noted when ferrocene is mixed with cobaltocenium in ionic liquids. ${ }^{20}$

Further demonstration of this non-linear behaviour was obtained by UV-Vis spectroscopy. Ferrocene-iodine charge transfer complexes are known in non-aqueous solvents, ${ }^{16 a}$ and extinction coefficient of $\mathrm{I}_{2}$ and $\left[\mathrm{I}_{3}\right]^{-}$are extremely structureand solvation-sensitive. ${ }^{21}$ Fig. 4 (a) displays the titration of $\mathrm{I}_{2}$ with $\mathrm{I}^{-}$(introduced as [Emim]I), yielding the characteristic absorption bands. ${ }^{16 d, 22}$ Stoichiometric quantities of $\mathrm{I}_{2}$ and $\mathrm{I}^{-}$ resulted in quantitative formation of $\left[\mathrm{I}_{3}\right]^{-}$, as represented by the absorption maxima. Fig. 4(b) displays the same spectra of
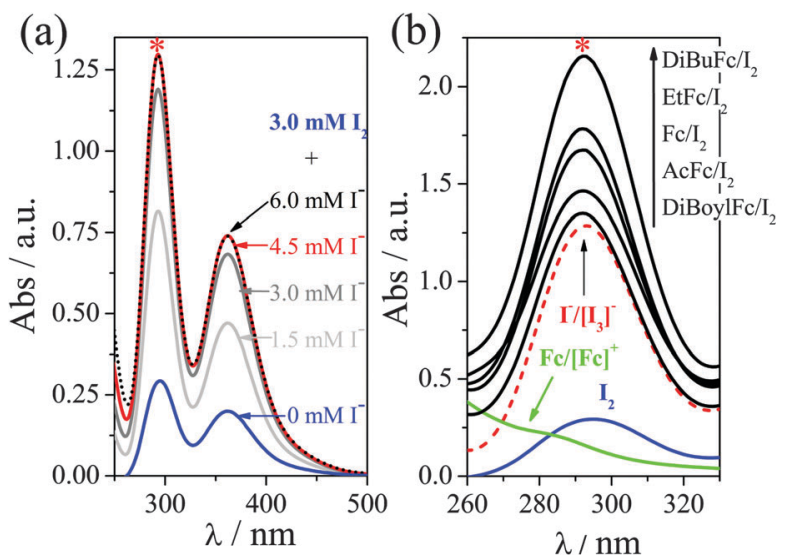

Fig. 4 UV-Vis absorption spectra of (a) $3 \mathrm{mM} \mathrm{I}_{2}$ in presence of various [Emim]l concentrations, and (b) $3 \mathrm{mM} \mathrm{I}, 3 \mathrm{mM} \mathrm{Fc} / 3 \mathrm{mM} \mathrm{Fc}^{+}, 3 \mathrm{mM}$ $\mathrm{I}^{-} / 3 \mathrm{mM}\left[\mathrm{I}_{3}\right]^{-}(---)$as well as $3 \mathrm{mM}$ of the 5 [ferrocenium] [l $\left.{ }_{3}\right]$ samples. All in [Emim] $\left[\mathrm{NTf}_{2}\right]$. Pathlength $1 \mathrm{~mm}$. 
$\mathrm{I}_{2}$ and $\mathrm{I}_{2} / \mathrm{I}^{-}$, overlaid with the spectra for $\mathrm{Fc} /[\mathrm{Fc}]\left[\mathrm{PF}_{6}\right]$ and all five "ferrocenium triiodide" salts (as $3 \mathrm{mM}$ ferrocene and $4.5 \mathrm{mM}_{2}$ ). All five ferrocene/iodine mixtures should have an absorbance below that of $3 \mathrm{mM}\left[\mathrm{I}_{3}\right]^{-}$, as they will introduce $3 \mathrm{mM}\left[\mathrm{I}_{3}\right]^{-}$or less, based upon the equilibrium in eqn (2). As the absorbance of the ferrocenium triiodides exceed this in every case, the solvation environment of $\left[\mathrm{I}_{3}\right]^{-}$in the $\mathrm{IL}$ is clearly altered upon introduction of ferrocene species.

An interaction between ferrocene and iodine species will result in an additional entropic change upon a redox process occurring, relative to the individual species. These significant interactions can therefore explain the synergistic enhancement apparent in the $S_{\mathrm{e}}$ coefficient. It is logical that the electrondeficient ferrocenes would display more significant chargetransfer complexation with the electron-rich and highly polarisable iodine species. This increased interaction mirrors the observed synergistic enhancement in the $S_{\mathrm{e}}$ coefficient, with DiBoylFc predicted to interact with iodine the most and also displaying the highest $S_{\mathrm{e}}$ coefficient of $1.67 \mathrm{mV} \mathrm{K}{ }^{-1}$. This $S_{\mathrm{e}}$ coefficient compares favourably with the highest $S_{\mathrm{e}}$ value ever reported in the IL [Emim] $\left[\mathrm{NTf}_{2}\right]$, which was ca. $1.66 \pm 0.02 \mathrm{mV} \mathrm{K}^{-1}$ for $100 \mathrm{mM}$ $\left[\mathrm{Co}^{\mathrm{II} / \mathrm{III}}[\mathrm{bpy}]_{3}\right]\left[\mathrm{NTf}_{2}\right]_{2 / 3} \cdot{ }^{5 b}$ The reported $\left[\mathrm{Co}^{\mathrm{II} / \mathrm{III}}[\mathrm{bpy}]_{3}\right]\left[\mathrm{NTf}_{2}\right]_{2 / 3}$ was deliberately chosen to result in the most significant entropy change upon changing oxidation state, with purely the cationic component contributing. In the case of the ferrocenium triiodides, we have demonstrated that two common, widely available, relatively poor thermoelectrochemical redox mediators (by conventional knowledge and approaches) can be combined to result in an excellent system when combined.

In conclusion, this work has investigated the thermoelectrochemistry of mixed redox couples (ferrocene and iodine) for the first time. These two couples were found to interact even in dilute solution, resulting in a synergistic thermoelectrochemical response. This likely stems from observed charge-transfer complex formation, which must introduce additional entropic changes when one component undergoes a redox process, additional to simple restructuring of the surrounding ionic liquid. This work therefore represents a new approach towards the development of thermoelectrochemical systems, with the value of $1.67 \mathrm{mV} \mathrm{K}^{-1}$ for [DiBoylFc] $\left[\mathrm{I}_{3}\right]$ being one of the highest reported $S_{\mathrm{e}}$ value for a solute in the ionic liquid [Emim] $\left[\mathrm{NTf}_{2}\right]$.

The Australian Research Council (ARC DECRA DE130100770) is acknowledged for funding. The authors would like to thank the Australian National Fabrication Facility (ANFF) for equipment access.

\section{Notes and references}

1 C. B. Vining, Nat. Mater., 2009, 8, 83-85.

2 D. M. Rowe, Thermoelectrics handbook: macro to nano, CRC/Taylor \& Francis, Boca Raton, 2006.
3 M. S. Romano, N. Li, D. Antiohos, J. M. Razal, A. Nattestad, S. Beirne, S. Fang, Y. Chen, R. Jalili, G. G. Wallace, R. Baughman and J. Chen, Adv. Mater., 2013, 25, 6602-6606.

4 R. Hu, B. A. Cola, N. Haram, J. N. Barisci, S. Lee, S. Stoughton, G. Wallace, C. Too, M. Thomas, A. Gestos, M. E. Cruz, J. P. Ferraris, A. A. Zakhidov and R. H. Baughman, Nano Lett., 2010, 10, 838-846.

5 For example: (a) T. J. Abraham, D. R. MacFarlane and J. M. Pringle, Chem. Commun., 2011, 47, 6260-6262; (b) T. J. Abraham, D. R. MacFarlane and J. M. Pringle, Energy Environ. Sci., 2013, 6, 2639-2645; (c) V. Zinovyeva, S. Nakamae, M. Bonetti and M. Roger, ChemElectroChem, 2014, 1, 426-430; (d) M. Bonetti, S. Nakamae, B. T. Huang, T. J. Salez, C. Wiertel-Gasquet and M. Roger, J. Chem. Phys., 2015, 142, 244708.

6 T. I. Quickenden and Y. Mua, J. Electrochem. Soc., 1995, 142, 3985-3994.

7 A. Gunawan, C. H. Lin, D. A. Buttry, V. Mujica, R. A. Taylor, R. S. Prasher and P. E. Phelan, Nanoscale Microscale Thermophys. Eng., 2013, 17, 304-323.

8 B. Burrows, J. Electrochem. Soc., 1976, 123, 154-159.

9 H. A. H. Alzahrani, J. J. Black, D. Goonetilleke, J. Panchompoo and L. Aldous, Electrochem. Commun., 2015, 58, 76-79.

10 H. M. Yau, A. K. Croft and J. B. Harper, Faraday Discuss., 2012, 154, 365-371.

11 L. Aldous, A. Khan, M. M. Hossain and C. Zhao, Catalysis in Ionic Liquids: From Catalyst Synthesis to Application, The Royal Society of Chemistry, 2014, pp. 433-473.

12 (a) E. I. Rogers, D. S. Silvester, D. L. Poole, L. Aldous, C. Hardacre and R. G. Compton, J. Phys. Chem. C, 2008, 112, 2729-2735; (b) C. P. Fu, L. Aldous, E. J. F. Dickinson, N. S. A. Manan and R. G. Compton, ChemPhysChem, 2011, 12, 1708-1713; (c) C. P. Fu, L. Aldous, E. J. F. Dickinson, N. S. A. Manan and R. G. Compton, Chem. Commun., 2011, 47, 7083-7085; (d) C. P. Fu, L. Aldous, E. J. F. Dickinson, N. S. A. Manan and R. G. Compton, New J. Chem., 2012, 36, 774-780.

13 (a) E. I. Rogers, D. S. Silvester, L. Aldous, C. Hardacre and R. G. Compton, J. Phys. Chem. C, 2008, 112, 6551-6557; (b) E. I. Rogers, I. Streeter, L. Aldous, C. Hardacre and R. G. Compton, J. Phys. Chem. C, 2008, 112, 10976-10981.

14 For example; (a) B. Gélinas and J. C. Forgie, and D. Rochefort, J. Electrochem. Soc., 2014, 161, H161-H165; $(b)$ B. Gélinas and D. Rochefort, Electrochim. Acta, 2015, 162, 36-44; (c) Y. Funasako, T. Mochida, T. Inagaki, T. Sakurai, H. Ohta, K. Furukawa and T. Nakamura, Chem. Commun., 2011, 47, 4475-4477; (d) T. Inagaki and T. Mochida, Chem. Lett., 2010, 39, 572-573.

15 C.-T. Li, C.-P. Lee, C.-T. Lee, S.-R. Li, S.-S. Sun and K.-C. Ho, ChemSusChem, 2015, 8, 1244-1253.

16 (a) H. Grimes and S. R. Logan, Inorg. Chim. Acta, 1980, 45, L223-L224; (b) S. R. Logan and M. R. Welsh, Z. Phys. Chem., 1986, 148, 215-220; (c) S. R. Logan and M. R. Welsh, J. Chem. Soc., Faraday Trans. 1, 1988, 84, 1259-1265; (d) H. M. A. Salman, M. R. Mahmoud, M. H. M. Abou-El-Wafa, U. M. Rabie and R. H. Crabtree, Inorg. Chem. Commun., 2004, 7, 1209-1212; (e) J. R. B. Hanna and S. R. Logan, J. Photochem., 1979, 10, 267-271; $(f)$ E. W. Neuse and M. S. Loonat, J. Organomet. Chem., 1985, 286, 329-341.

17 J. P. Hurvois and C. Moinet, J. Organomet. Chem., 2005, 690, 1829-1839.

18 T. Migita, N. Tachikawa, Y. Katayama and T. Miura, Electrochemistry, 2009, 77, 639-641.

19 A. Gunawan, H. C. Li, C. H. Lin, D. A. Buttry, V. Mujica, R. A. Taylor, R. S. Prasher and P. E. Phelan, Int. J. Heat Mass Transfer, 2014, 78, 423-434.

20 M. J. A. Shiddiky, A. A. J. Torriero, C. Zhao, I. Burgar, G. Kennedy and A. M. Bond, J. Am. Chem. Soc., 2009, 131, 7976-7989.

21 K. Kaya, N. Mikami, Y. Udagawa and M. Ito, Chem. Phys. Lett., 1972, 16, 151-153.

22 R. E. Rundle, J. F. Foster and R. R. Baldwin, J. Am. Chem. Soc., 1944, 66, 2116-2120. 